\title{
Polyethylene Imine Derivatives ('Synzymes') Accelerate Phosphate Transfer in the Absence of Metal
}

\author{
Frédéric Avenier, Josiel B. Domingos ${ }^{\S}$ Liisa D. Van Vliet and Florian Hollfelder* \\ Contribution from the Department of Biochemistry, University of Cambridge, Cambridge CB2 1GA, \\ United Kingdom, EU.
}
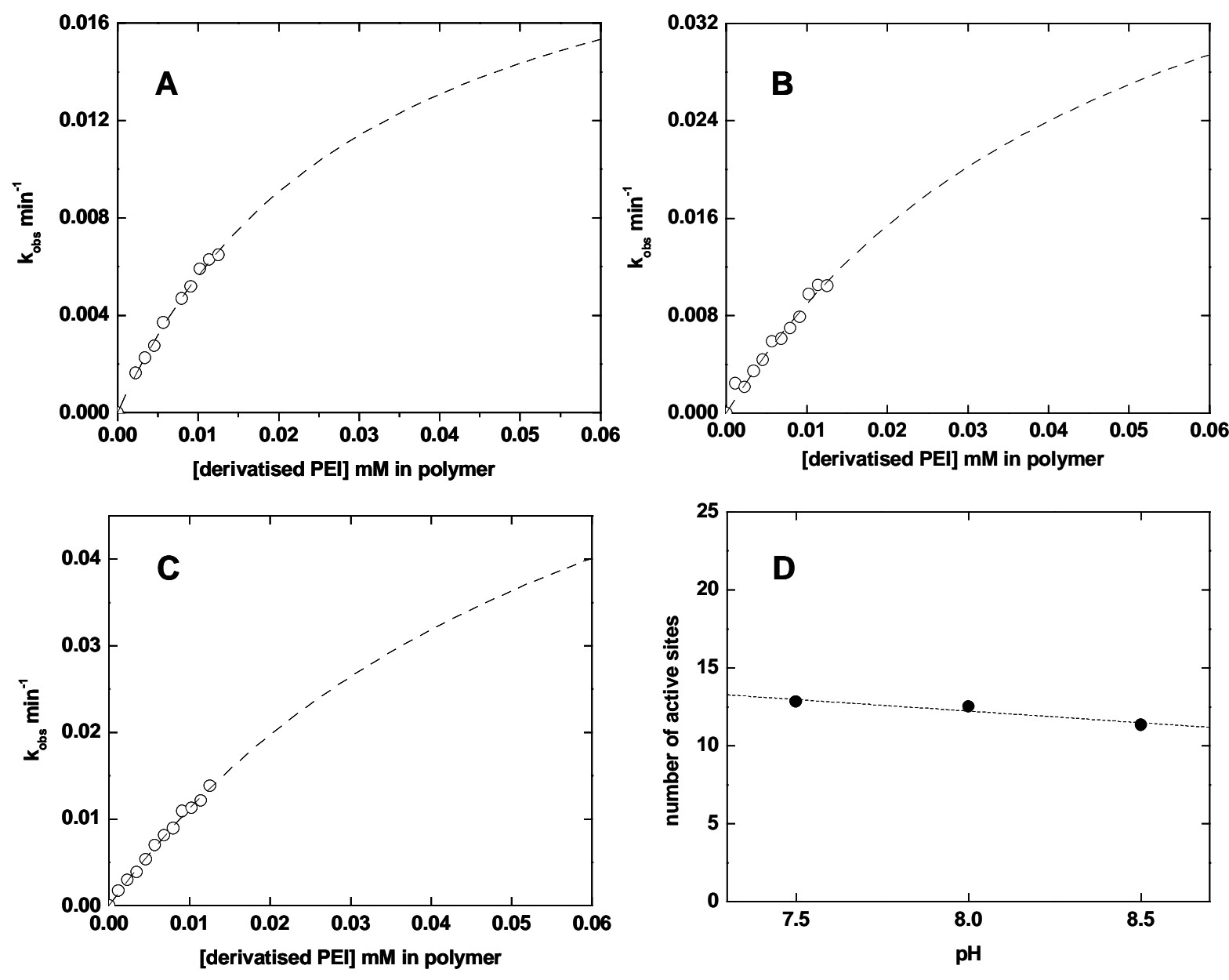

Figure S1. Determination of the Number of active site per polymer near the optimum $p H$. Single turnover kinetics for D9 with an excess of enzyme over substrate ([synzyme] $=0-12.6 \mu \mathrm{M}$; $[\mathrm{S}]=25$ $\mu \mathrm{M})$ at (A) $\mathrm{pH} 7.5,(\mathbf{B}) \mathrm{pH} 8.0$ and (C) $\mathrm{pH}$ 8.5. (D) Number of active sites depending on $\mathrm{pH}$. 

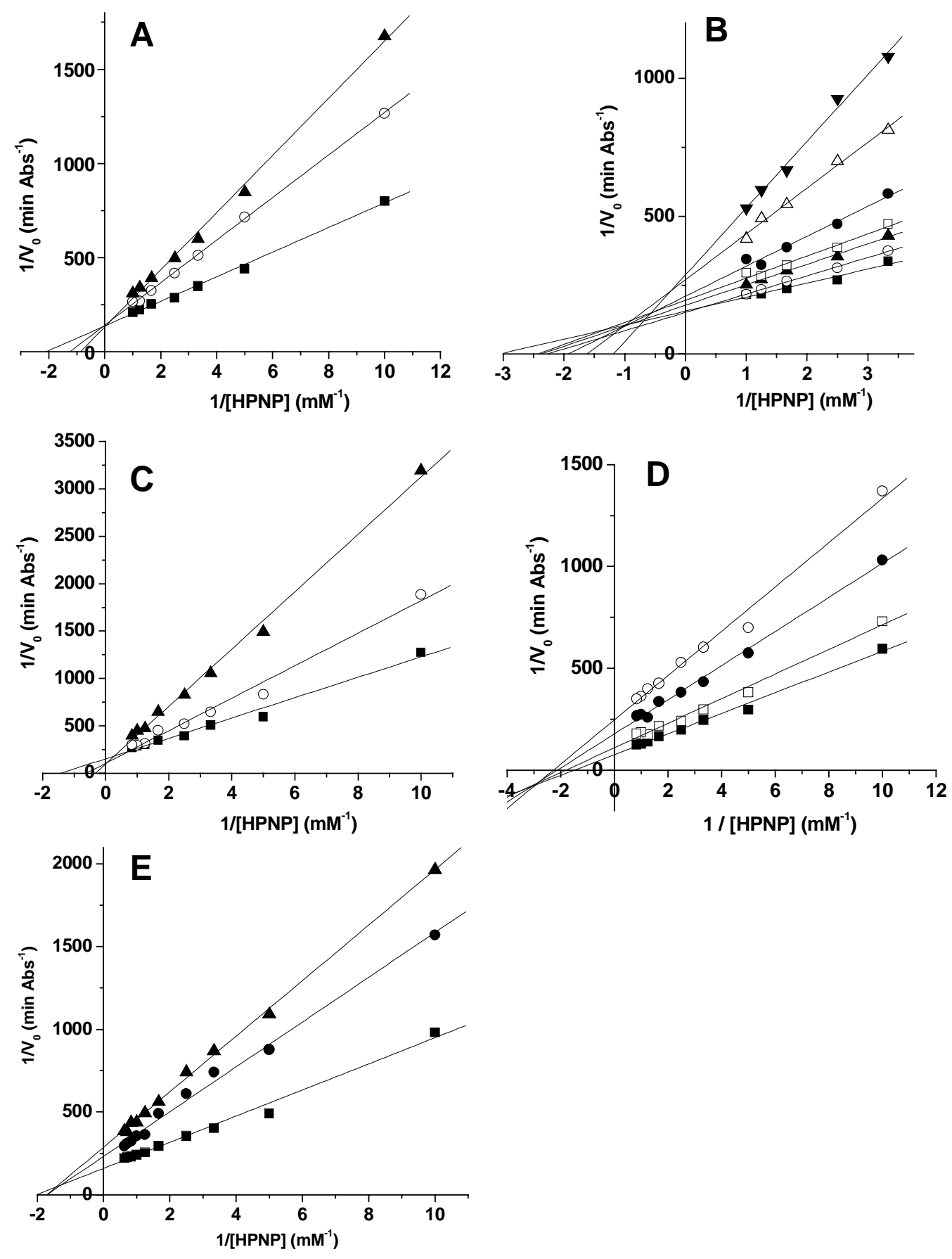

Figure S2. Lineweaver-Burk representation of the inhibition of D9 by (A) inorganic phosphate, (B) sodium chloride, (C) 4-nitrophenyl phosphate, (D) 1-naphthyl phosphate and (E) ethyl-(4-nitrophenyl) phosphate at different concentrations of inhibitors. Conditions: [HEPES] $50 \mathrm{mM}$, [polymer] $=3.44$ $\mu \mathrm{M}, \mathrm{pH}$ 7.85. Data are plotted as a Lineweaver-Burke representation in order to visualize the inhibition patterns, but the inhibition constant displayed in table 2 have been calculated from more reliable nonlinear least square fits using the Michaelis-Menten equation. 

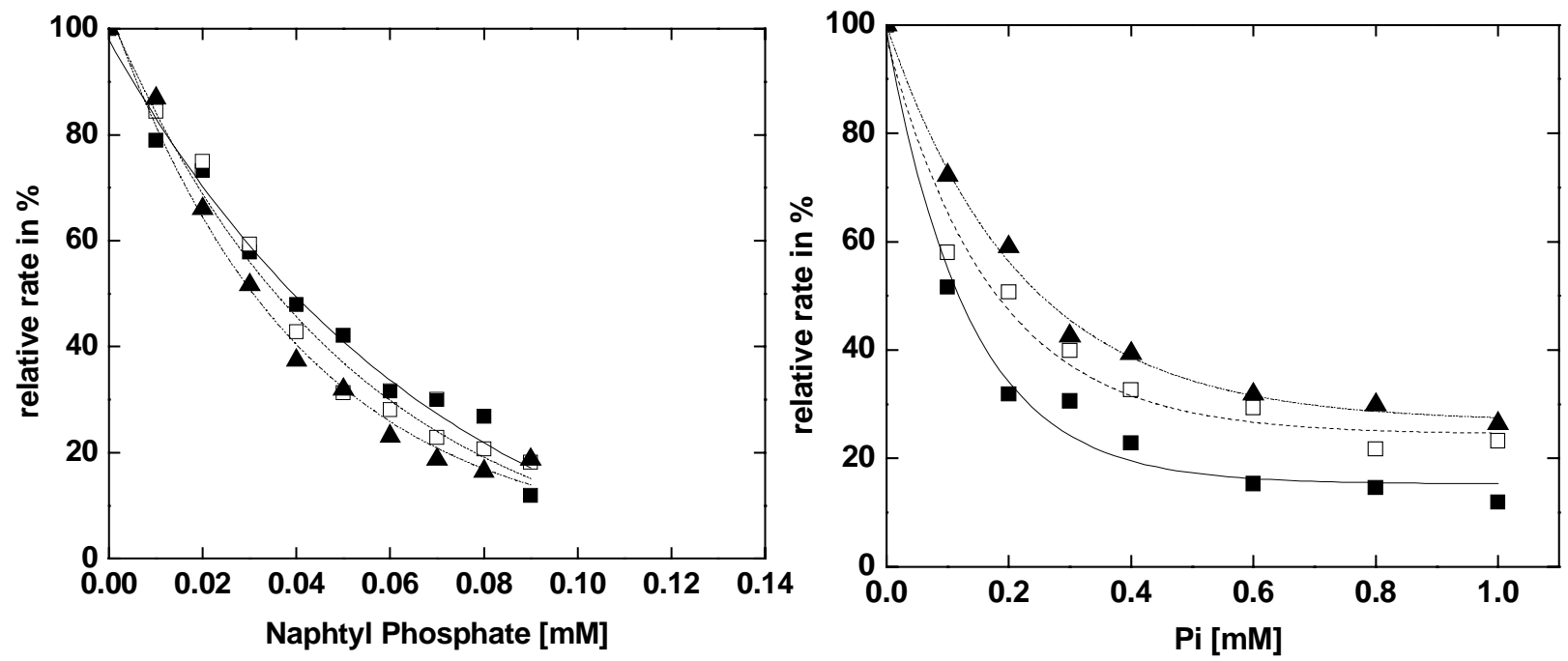

Figure S3. Inhibition profile for D9 depending on $\mathrm{pH}(\mathbf{(}) \mathrm{pH} 7,(\square) \mathrm{pH} 7.5$ and ( $\mathbf{\Delta}) \mathrm{pH} 8)$ by (A) 1naphthyl phosphate and (B) inorganic phosphate. Conditions: [HEPES] $50 \mathrm{mM}$, [polymer] $=3.44 \mu \mathrm{M}$. 